\title{
The political shaping of teacher education in STEM areas
}

\section{Tony Brown}

School subjects like Mathematics and Science have been re-conceptualised as part of the armoury of Science, Technology, Engineering and Mathematics (STEM), responding to a commonly conceived purpose of supplying the world's workforce with the resources needed to support economic wellbeing through Technological development (Tytler, Swanson and Appelbaum, 2015; Freeman, Marginson and Tytler, 2015). With the metaphorical underpinning of being straight and strong, the centre from where everything grows, the acronym STEM drives an insistent and well funded project of advancing our understandings in those areas of the curriculum. Schooling is increasingly shaped and judged by its perceived capacity to deliver success in terms of international competitiveness as measured in testing programs such as the OECD Programme for International Student Assessment (PISA) or Trends in Mathematics and Science Study (TIMSS), which have perhaps privileged Western concerns. Governments around the world, however, have been jockeying for a better position in the resulting league tables, which are supposedly indicative of wider economic competitiveness. They have been seduced by the appeal of raising standards in a statistically defined world. What had been introduced to measure school performance, however, now defines what it is and polices its boundaries. That is, such comparisons have transformed the content of what they compare and the demands on the teachers preparing to meet these newly defined challenges. A possible consequence of this has been an overly restrictive understanding of mathematics and science through being referenced to their socio-economic potential. But whilst these subjects have become a priority across nations through research funding and the like, growth in these subjects is hampered by a shortage of people qualifying either because of perceived or actual difficulty, or because of their lack of popularity for other reasons. Yet policy responses to these economic priorities and actual teacher supply have been conceptualised in diverse ways across different countries.

This chapter examines some examples of policy initiatives consequential to this recasting of mathematics and science. It firstly explores the impact on teacher education in these areas with reference to two very different state-led responses to changing teacher preparation. In some countries teacher education increasingly comprises a vocational employment-based model of training located primarily in schools. England is a prominent example, with similar models being introduced in New Zealand and the United States. This approach is in sharp contrast to models followed in continental Europe subject to the Bologna Process, where student teachers spend much more time in university (e.g. five years in Finland where a masters' degree is required). These two approaches reveal radically different conceptions of how teacher quality might be improved in the name of international competitiveness. In the first, teacher education has been wrested from its traditional home within the academy where universities play a support role to what has become "school-led" training where government funds for teacher education have been diverted to schools. Teacher professional identity has been referenced to skill development within this frame and the wider assessment culture. The second model, meanwhile, is similarly concerned 
with "raising teacher quality ... (but specifically) in a way which responds to the challenges of lifelong learning in a knowledge based society" (ENTEP, Dimitropoulos). It is characterised by reinvigorated faith in academic study and promotion of individual teachers, where a pedagogical dimension in included from the outset of undergraduate studies, but with relatively brief periods spent in school.

Secondly, the chapter focuses more directly on how policy administration relates to ideological conceptions of the task of teaching. Who does the curriculum target and why? For example, a major report suggested that school science in Europe is often conceptualised as a necessary transit for those following scientific study at university whilst neglecting "the needs of the majority of students who require a broad overview of the major ideas that science offers, how it produces reliable knowledge and the limits to certainty" (Osbourne and Dillon, 2008). Technology, as a school subject, is a weaker partner in its STEM membership with its more precarious place on the curriculum (Bartex, 2011). The case of US reform movement in mathematics is taken in this chapter as a key example of how ideological differences create alternative priorities in conceptualising the challenges of education, then compete in determining teacher education practices and how teacher practice relates to curriculum structure. That is, does education constitute the delivery of basic skills or are students required to build their own constructions? The "mathwars" in the USA were a particular manifestation of this divide. Similarly, teachers are given varying responsibility across countries as to their responsibility to build their own constructions of what it is to teach. Similar debates are also alive in science teacher education across Europe (Education, Audiovisual and Culture Executive Agency, 2011).

The chapter will commence by outlining the way in which two radically alternative conceptions of teacher education have emerged in Europe both seemingly in response to the ascendance of international comparisons as a framework of reference in deciding policies motivated by assumptions of education being linked to economic wellbeing. The chapter outlines how both models trouble common assumptions about the role of universities in teacher education and how market conditions can undermine educational principles and customary practice. In the second part attention turns to how ideological conceptions of learning and teaching drive teacher development and identifications with particular modes of practice. Anecdotal material from teacher educators and trainees is drawn from a study spanning UK, New Zealand, Germany, Spain, Sweden, Finland and Japan (Brown, Rowley and Smith, 2014, 2015ab).

\section{Alternative conceptions of teacher education across school and university settings}

In England, atypically perhaps among other countries, most teacher education has moved into schools with universities playing a more peripheral role. This is ostensibly a lower cost approach to teacher education that may appeal to other countries. The point of this section, however, is not to invite international readers to try this at home. 
The more general issue relates to how teacher education knowledge is conceptualised, how this shapes practice but also questioning how and why university contributions have been conceptualised in the way that they have been, and if they deliver on their promise. The chapter asks whether the choice between the benefits of school-based training and of university led teacher education is so obvious as it may first appear. By taking an atypical perspective on more familiar models the rationale for these models might be seen differently, whilst raising the more generic issue of how learning to teach happens differently across university and school locations.

\section{School based teacher education}

University teacher education in England generally has been redefined through new priorities determined by, among other things, budgetary constraint, problems with teacher supply (Rowlands and Ruthven 2011) and perceived school performance as compared with other countries (DfE, 2010). The teacher education function has been re-distributed through governmental mandate to include professional and subject mentors within the school setting challenging the more familiar university-based models. These mentors are themselves classroom teachers with their own classes to teach. This arrangement is thought to provide immediate opportunity for student teachers to develop classroom skills (DfE, 2010). The student teachers spend much less time at university with tutors, where they have some limited scope to reflect on their practice and to consider educational theory (Smith, Hodson and Brown 2013a). Something of the order of thirty days are spent at a university during a one-year postgraduate "training" course, where the chief university responsibility is oversight and accreditation for a process primarily administered by schools.

University teacher educators and school mentors, however, may have very different priorities for their roles in teacher training, such as those relating to how subject knowledge is understood, meeting the demands of testing, effectively using materials, learning a range of pedagogical strategies or building personal involvement in the subject. There are different ways of understanding the disciplinary knowledge that teachers need. Schools may prioritise the immediacy of classroom practice or following centralised guidance; universities may prioritise the more intellectually based elements such as pedagogical subject knowledge, building professional autonomy, or meeting the demands of formal qualification (Hobson, Malderez and Tracey 2009; Hodson, Smith and Brown 2011). Hitherto, relatively little research has been carried out on how increased school-based training supports the pedagogical subject knowledge aspects of teacher education, and how they are conceptualised, prioritised and enacted, so that further interventions could be better informed. Brown, Rowley and Smith (2015a) discuss a few instances of subjects being reshaped to fit their new state of priority. Yet overall we know little about how new teachers understand subject knowledge following training across school and university settings (Rowland, Turner, Thwaites and Huckstep 2009); and, how student teachers of science conceptualise their own teaching in schools (Heywood and Parker, 2010).

Meanwhile, the tendency in some countries of taking charge of school practices through a multitude of regulatory devices, such as through frequent testing, prescriptive curriculum and school inspection (Askew, Hodgen, Hossain, and Bretscher 2010; Brown 2011) has resulted in mathematics and scientific subject knowledge 
becoming understood through a culture of performativity (Pampaka, Williams, Hutcheson, Wake, Black, Davis and Hernandez-Martinez 2012). This insistence on following centralised documents has deflected attention from knowing how the redistribution of teacher education has resulted in student teachers actually understanding and meeting the professional challenges they face.

These changing policies affect the challenges faced by teacher-educators and 'school mentors', and in turn influence student teachers' conceptions of subject knowledge and its teaching. The policies also impact on the identity of the student teachers. Are they student teachers engaged in an educative process developing the ability to lead curriculum initiatives as they later become professional teachers? Or are the trainees fulfilling the requirements of training, working to the current models of school practice, as specified by the government? That is, are teachers curriculum makers, or curriculum implementers (Schwab, 1983; Clandinin and Connelly, 1992; Craig and Ross, 2008)? One is moved to suggest that school-based trainees are being prepared primarily for the latter and will take their chances in being carried along in the future rather than having been prepared directly to address changes in professional circumstances. We now turn to the contrasting situation in continental Europe. Here we shall find an approach that has provoked some concern through its lack of connection to school practice.

\section{University based teacher education}

There are still many regional variations across Europe yet: "Almost all countries introduced reforms in initial primary teacher education after the initiation of the Bologna Process (1999)" (ENTEP, Dimitropoulos), similarly for secondary subject teachers, and half of pre-primary sectors of education. This has led to the establishment of a "European Teacher Education Area". The model is motivated by sharing good practices and creating mutual trust in the teaching qualifications awarded across member states with view to enabling shared accreditation and greater mobility across European countries. This approach has disappointed some students studying primarily to get a job in a given location. The lengthy academic training often conducted by people with relatively little experience of schools can seem distant from the more practical challenges ahead. In Germany teachers need to get through four to five years prior to being admitted to the school practicum phase of 18 months to 2 years. In Spain all primary teachers study at university for four years including short periods in school. Yet this investment retains wide support across European nations. As one German primary mathematics teacher educator put it. "The university is a space to question. What for? Why? How could it be different? Rather that being in a state of permanent emergency (as in school-based work) ... A teacher is not just a craftsman." This intensification of the academic component can be seen as a further distancing from practical concerns for student teachers in those countries (Hudson and Zgaga, 2008). Once qualified, however, following an extended school placement after the academic component has been completed, rather more professional autonomy can be asserted than in the policy dominant approach in England. That is, the teachers are given more responsibility for making local decisions thus setting the curriculums to a greater extent. 


\section{Contrasting the two models}

Lower cost school-based teacher education may appeal to an increasing number of governments in building and influencing the practice of their teaching forces. But three questions immediately present themselves: Does it provide a viable alternative to university based teacher education? Does it alter the composition of the pedagogical subject knowledge it seeks to support? Is it low cost, or at least good value for money? The particular impact on different school subjects as a result of these contrasting approaches relates to the way in which conceptions of the subjects derive from where understandings of them are developed, whether in schools or in universities. For those in schools little more may be done than enable teachers to work through commercial schemes as implementers of curriculum. For those following university intensive courses relatively low attention is given to the practical school aspects during the university element where the creative aspect is not extensive. To summarise key issues emerging in our study one might highlight:

\section{Some limitations of school based teacher education}

a) Performance driven assessment affects the nature of subject knowledge.

School-based practice has been driven by the need to meet assessment requirements. Trainee teachers are given fewer opportunities to conceptualise other modes of practice. By emphasising the elements that are more likely to be tested subject knowledge may be diminished. Current conceptions of school mathematics and science for example are supported but only in a narrow way if judged primarily by their ease of assessment. Less emphasis is placed on pupils being able to adjust to future demands. This emphasis drives compliance to external demands in which student teachers and their pupils play a smaller part in the construction of the subjects. There is a culture of "getting it done" or "giving the method" rather than teaching for understanding: "Does that make sense... is that realistic?" An occasional decision to "step back" from the formal in the name of building understanding, "light bulbs were going on everywhere", was seen as an exception rather than the norm in the anecdotal material (Smith, Hodson and Brown 2013b). The thrust in English schools over recent years has been towards supporting skills-based agenda. For example, following a governmental led "back to basics" campaign England succeeded in moving from 18th to 7th position in mathematics on TIMSS in 2007, whilst dropping in its rankings from 8 th to 25 th on more problem focused measures, such as, PISA in 2006. Being a teacher is understood in terms of shaping subject knowledge in line with curriculum specification to meet the required forms to suit the given class composition. This external specification can lead to some issues of continuity in education in England where successive phases (e.g. exams at 16+, 18+ and university degree level mathematics, in England) each phase works to a different discursive frame as to how teachers, students and mathematics are each understood.

\section{b) School based training can nurture narrow administrative conceptions of teaching.}

For student teachers on school-based routes, being initiated into teaching by way of their placement schools' insistence on following specific textbooks "page after page" in some instances diverted student teachers from trying out ideas introduced in 
university sessions. This administrative insistence on a clearly defined but narrow route resulted in an antipathy to risk. This is perhaps unsurprising for primary students (those teaching ages 5-11) who have usually not gone beyond their 16+ examinations in mathematics or science. Yet even for secondary teachers (those teaching ages 1116) with formal mathematics backgrounds there was some trepidation in relation to the mathematical demands of teaching. Many student teachers in mathematics and science now feel the need to follow special courses to enhance their subject content knowledge in advance of commencing formal teacher education.

Yet these occasionally negative assessments of school based training limiting the development of subject knowledge is countered by some additional pedagogical factors that were seen as conferring some benefit:

\section{Some benefits of a stronger school role in teacher education}

\section{c) Practice-centred learning can improve participation in schools}

Some school practitioners see virtue in employment-based models because of their immediate concern with the demands of the classroom. A mentor responsible for overseeing such students in a demanding inner city location spoke of how the school's greater input allowed more investment of support time aimed at enabling new teachers to survive and function in difficult circumstances (cf, Clandinin, Long, Schaefer, Downey, Pinnegar, McKenzie and Wnuk, 2015). For a school with a welldeveloped scheme of work, student teachers and pupils alike may benefit from the student working to a clearly defined structure as a shared enterprise with colleagues. Such a community of practice (Wenger, 2000) may supply genuine opportunity for students to experience an insider perspective on being a teacher. As one student put it: "the behaviour of the students is challenging, but we're encouraged to take risks and try out activities". A number of school-based students were offered jobs by their placement schools prior to the course being completed. This was good for the school to have found a suitable teacher in an area of persistent teacher supply issues, but could reduce the student's motivation to exceed the already limited academic demands.

d) The enforcement of a centralised curriculum supports a collective vision of learning The motivation behind the somewhat insistent centralised curriculum was centred in administrating the many teachers who lacked adequate subject content knowledge and professional capabilities to work without explicit support towards a collective set of ambitions. Any collective arrangement requires compromise and unnecessary guidance to those teachers who were adequately skilled was seemingly a low price to pay for wider participation in a shared arrangement. STEM education research is sometimes predicated on finding more refined pedagogical strategies for a teacher to follow whilst neglecting the reality of teacher recruitment in terms of individual skill. Alternatively, student teachers might creatively identify with approaches spanning a larger population of teachers as a mode of support for those with lower confidence or specialist background in STEM areas.

e) Research is directly focused on developing practice 
Many instances of STEM education research are finely tuned on issues unlikely to be encountered in preservice training courses. Within the apprenticeship model described, however, the students themselves were participating in forms of practitioner-oriented research made possible by the immediacy of on going school practice (e.g. Sorenson, 2014; Hanley and Brown, 2016). The university element that had often been seen as irrelevant by many students in the first instance later became an effective critical platform for inspecting and reflecting on their own school practices. This platform comprised an opportunity to articulate the shaping of practice from an alternative location in which everyday demands could be understood against a wider context. Rather than thinking what would work in the current placement school, the concern became that of thinking more broadly about what would work for them across schools more generally. So rather than student teachers being subservient to a map dictating the format of their practices, they had some influence over how the map was created and how it could be seen as guiding their generic practices as a teacher. These opportunities to connect school with university input featured less in the Bologna Process as a result of university and school phases being sequential.

Having focused on how the teacher education curriculum is conceptualised and distributed across university and school locations the chapter now considers the interface between the curriculum and its users.

\section{Conceptions of policy led curriculum change}

With the introduction of any new initiative there comes an implicit assumption that it will bring improvement over the previous regime. More specifically, teachers' orientations to teaching are identified as influential factors in mediating the strength of an initiative's effect. Evaluations of a major curriculum initiative in England refer to teachers' deep-seated beliefs, which are left largely unchallenged (e.g. Brown, Askew, Millett and Rhodes, 2003) such that structural changes can be "bolted on" to existing practice (Galton, 2002). Similarly, Brown, Millet, Bibby, and Johnson (2000) have asserted that any such development will have multiple interpretations made of its impact. Local context also appears to influence the nature of classroom implementation: specifically, this could be teachers' perceptions of their schools' priorities within the wider education system (Kynigos and Argyris, 2004; Ng, LopezReal, and Rao, 2003; Krogh and Thomsen, 2005) or their beliefs about pupils' needs (Sztajn, 2003; Hammon, 2011; Wells, 2012). Senger (1999), Skott (2001), and Sorensen, Newton and McCarthy (2012), meanwhile, provide models that help to illuminate shifts in teachers' thinking and practice as a recursive interchange between beliefs and how they talk about teaching and experimentation. One specific aspect that has drawn attention is the quality and variation of interactions observed in whole class teaching (e.g. Brown et al., 2003; Burns and Myhill, 2004). Still other pertinent and diluting factors include teachers' lack of detailed awareness of how they operate (Sahin, Bullock, and Stables, 2002; Torrance and Pryor, 2001) and for how long they have been teaching. Inexperienced teachers are more likely to engage fully with new curricula (Remillard and Bryans, 2004), whilst experienced teachers can find it very 
difficult to alter practice (Romberg, 1997) as personal beliefs about practice are based on compelling evidence derived from daily classroom experience (Handal and Herrington, 2003). Voogt and Torneur (2015) and Alayyar, Fisser and Voogt (2011) consider the challenge of introducing technology into the curriculum in a number of countries. Tondeur, Siddiq, Scherer and van Braak (2016) discuss the case in African school education.

Asking teachers to move from one teaching approach to another can never be regarded as a straightforward substitution (cf. Fullan, 2001). Nevertheless, for those charged with setting policy, there is often a perceived obligation to do something. And often this involves doing something big. In the United Kingdom, New Zealand and Australia, governments have prescribed detailed mathematics and science curricula for students and teachers alike, along with associated industries of preparation of materials. In terms of research literature, however, considerably more information is readily available about the effect of major curriculum reform in the United States, where there is also a considerable emphasis on the widespread adoption of new curriculum materials as a primary strategy for improving mathematical education (Remillard, 2005). And, this research has influenced the parameters through which curriculum reform and related research more generally has come to be understood. There is a need to question the common assumption that research is about encouraging movement towards some improved conception of teaching on the grounds that "improvement" is not a universal term. Rather, US reform has shaped research and practice domains in particular ways with commensurate conceptions of improvement.

US reform, more generally, is defined for mathematics in relation to National Council for Teaching Mathematics guidelines and is, for many teachers, seen as the transition from a transmission to a constructivist pedagogical approach (e.g. Fennema and Nelson, 1997). Constructivism, which has dominated international mathematics and science education research for the last three decades (Steffe and Kieran, 1994; Brown, 2001, Anderson, 2002), is characterised by "genuine mathematical problems for students to solve" (Lloyd, 1999, p. 228) and a focus on "conceptual understanding" (Wilson and Goldenberg, 1998, p. 269). Simon and Tzur (1999) and Tzur, Simon, Heinz, and Kinzel (2001) provide examples in which research is conceptualised as tracking progress towards some improved state of affairs. Many other studies focusing on how teachers respond to curriculum changes (e.g. Remillard and Geist, 2002; Van Zoest and Bohl, 2002, Rivera Maulucci, 2010; Goode and Margolis, 2011) centre their analysis on individuals shaping their practice in response to the perceived reform agenda, an agenda with which the authors positively identify and to which they readily subscribe, albeit with resistance from some quarters, such as "veteran" or "traditional" teachers who are unable to shift so fundamentally in terms of their beliefs as to what it is to be a teacher (Cohen, 1990; Lloyd, 1999).

US "reform" functions as an ideology insofar as it has set key parameters shaping discussion relating to curriculum innovation. It is a conception of improvement often presented as universally beneficial but actually it is culturally specific. It defines a professional space governed by certain assumptions as to how improvement might be achieved, whilst the limitations of its validity remain peripheral to this definition. Further, according to Sztajn (2003, p. 53), even within that culture: "Based on their concepts of students' needs, teachers select which parts of the reform documents are 
appropriate for their students" which translates as "children from upper socioeconomic backgrounds get problem solving, those from lower socioeconomic backgrounds undergo rote learning" (ibid). Viewed internationally, however, even such variation might be regarded as modest, framed as it is within the parameters of national boundaries, compulsory schooling infrastructure, economic status and a host of other societal assumptions. So there is a need to be cautious in observing how such assumptions have slipped into the apparatus for curriculum reform research more generally.

Yet even affinity with an ideology does not necessarily fix the mode of association or how that is viewed. In her study Remillard (2005, pp. 215-223) examined alternative ways in which teacher/curriculum interfaces are understood within the research literature. She contrasted "following or subverting" a curriculum text with "drawing on" a curriculum text or "interpreting" a curriculum text. In these three alternatives, the text is present in some form and teachers respond to it. Finally, however, Remillard considered how curricula might be understood as teachers participating with the text. For a teacher "enacting" a curriculum in this mode, she suggested that teacher and curriculum might be seen as mutually constitutive. Here, curriculum use is understood as participation with the text (pp. 221-223). She identifies this with "Vygotskian notions of tool use and mediation, wherein all human activity involves mediated action or the use of tools by human agents to interact with one another and the world" (cf. Cole, 1996). Such an approach is familiar within mathematics and technology education research (e.g. Lerman, 2000; Blanton, Westbrook, and Carter, 2005; Goos, 2005). But how might we unfold the features of this mutual constitution of teachers and curricula? Understood in terms of Foucault's (1989) notion of "discursive formation", both teacher and curriculum would be functions of how they are implicated in the stories that unite them. Both change as a result of curriculum development activity. Remillard (ibid) identifies some studies where teachers change or learn from their use of resources (Lloyd, 1999; Remillard, 2000; Van Zoest and Bohl, 2002). Yet teacher change can also be understood as being the result of increased compliance with respect to a curriculum initiative.

Reform cannot offer a trajectory with universal appeal or applicability. The "inquiry" methods associated with constructivist reform, characterised by greater learner and teacher autonomy, would be less acceptable in many Eastern or Pacific cultures where curricula, teacher/student roles and the collective good are defined differently (e.g. Brown et al, 2006). Further, the alleged autonomy understood within the "reform" agenda conflicts with the reality teachers have come to accept in some countries, assessed as they are through legislative documentation and recognised through the filter of their compliance with this. TIMSS and PISA were introduced to measure and compare school mathematics in different countries on a singular scale. Yet the resultant conceptions of school mathematics and science now define and police the boundaries of school mathematics and science. At a conference in 2011, a Mexican delegate spoke of how the exercises made her country subservient to American priorities (Garcia, Saiz and Rivera, 2011). An Ethiopian teacher educator depicted a situation in which teachers and students were obliged to engage with a form of study encased in pedagogical formations often unrecognizable in their country situation (Gebremichael, 2011). As seen, the United Kingdom has sacrificed its earlier facility with problem-solving approaches in order to meet newly understood 
content objectives. Meanwhile, a Finnish teacher educator indicated that her country's high performance in the exercises did not release her colleagues from having to reevaluate their practices in terms of the newly dominant international discourse (Krzywacki, 2011).

\section{Conclusion}

Pedagogical subject knowledge is a function of the educational domain in which it is encountered, and hence of the discourse that characterises that domain. That discursive structure can shape the actions of those subject to it. This chapter has documented some instances of STEM teaching practice resulting from modified conceptions of teacher education or development. The chapter has argued that the student teachers' conceptions of STEM subjects and their teaching of them can be crafted around the apparatus of administrative control, which are restrictive, expressed in terms of curricula compliance, or fitting in with existing school practices. This administrative restrictiveness in the name of policy implementation is potentially counter both to pupils achieving a positive disposition towards and functionality in the subjects in later study or professional life.

Specifically, pedagogical subject knowledge derives from particular types of encounter in a model of teacher education. In the school-based models the teachers' conceptions of subject knowledge developed without a great deal of explicit instruction from university specialists in the area. Rather the teacher education function was achieved through the student teachers being immersed in the infrastructure of schooling. In the approach described, the student teachers were primarily guided by their school mentors through centralised curriculum documentation, or by textbooks chosen by head teachers. That is, the students' mathematical pedagogical knowledge is derived from their own practice referenced to existing or required conceptions of subject knowledge and patterned on the associated apparatus. Their way of talking about subject knowledge mirrored the official discourse. As a consequence, there is a strong reproductive dimension to the student teachers' understanding of school subjects. Subject knowledge is defined within very tight boundaries that give it little space to be something else, such as constructions generated by the teachers or pupils themselves.

On the one hand, if mathematics and science are understood in terms of fixed results, levels and following procedures then little opportunity is provided for the student teacher to develop an autonomous professional attitude to the generation of mathematical or scientific enquiry in the classroom. Rather, the students are subject to an externally imposed curriculum as represented by the schools to whom they are assigned. They understand their own professionalism and identities in those terms.

On the other hand, school-based models provide an avenue through which student teachers and their tutors can experience the teaching of mathematics from new angles. In the school-based model described student teachers retained some possibility of inspecting their practices in school from an external site so that their insider experience of meeting immediate demands can be reviewed against a more holistic understanding of what they are trying to achieve. University tutors meanwhile, provided a responsive role in helping students to confront demanding classroom 
challenges in more creative ways, albeit in terms of administering mathematics and science to the prevailing models.

Ultimately, conceptions of improvement are very much a function of the country, or even local community, in which they apply and the state of affairs prevalent there. And it is this sense of contingency that underpins this chapter's focus on adjustments to new paradigms. In particular, it is unhelpful to suppose that we could identify trajectories of improvement that apply across all people and all phases of development. School subject knowledge has come to be a function of this newly described world, backed up by governments using these conceptions to set their policies. There is always a cost in the form of suppressions resulting from such generalist suppositions. To represent STEM subjects as universal, spanning nations and generations, comes at a price in terms of teachers' ability to identify with the modes of education privileged in such comparisons.

\section{References}

Alayyar, G., Fisser, P., \& Voogt, J. (2011). ICT Integration through design teams in science teacher preparation. International Journal of Learning Technology 6(2), pp 125-145.

Anderson, R. (2002). Reforming science teaching: What research says about inquiry. Journal of Science Teacher Education, 13(1), 1-12.

Askew, M., Hodgen, J., Hossain, S. \& Bretscher, N. (2010). Values and variables: A review of mathematics education in high-performing countries. London: The Nuffield Foundation.

Bartex, D. (2011). Dear Minister, This is why design and technology is a very important subject in the school curriculum. Design and Technology Education: An International Journal, 16(3), 9 - 18

Blanton, M., Westbrook, S., \& Carter, G. (2005). Using Valsiner's zone theory to interpret teaching practices in mathematics and science classrooms. Journal of Mathematics Teacher Education, 8(1), 5-33.

Brown, M. (2011). Going back or going forward? Tensions in the formulation of a new national curriculum in mathematics. Curriculum Journal, 22(2), 151-165.

Brown, M., Askew, M., Millett, A., \& Rhodes, V. (2003). The key role of educational research in the development and evaluation of the National Numeracy Strategy. British Educational Research Journal, 29(5), 655-667.

Brown, M., Millett, A., Bibby, T., \& Johnson, J. (2000). Turning our attention from the what to the how: The National Numeracy Strategy. British Educational Research Journal, 26(4), 457-472.

Brown, T. (2001). Mathematics education and language. Dordrecht: Kluwer.

Brown, T. \& Clarke, D. (2012). Institutional contexts for research in mathematics education. In Clements, M. Bishop, A., Keitel, C., Kilpatrick, J. \& Leung, F. (Eds.) Third International Handbook of Mathematics Education. Dordrecht: Springer.

Brown, T., Devine, N., Leslie, E., Paiti, M., Sila'ila'i, E., Umaki, S., \& Williams, J. (2006). Reflective engagement in cultural history: A Lacanian perspective on Pasifika teachers in New Zealand, Pedagogy, Culture and Society, 15(1). 
Brown, T. \& McNamara, O. (2011). Becoming a mathematics teacher: Identity and identifications. Dordrecht: Springer.

Brown, T., Rowley, H. \& Smith, K. (2014). Rethinking research in teacher education. British Journal of Educational Studies. 62 (3), 281-296.

Brown, T., Rowley, H \& Smith, K (2015a) Sliding subject positions: knowledge and teacher educators. British Educational Research Journal (online first)

Brown, T., Rowley, H. \& Smith, K. (2015b). The beginnings of school-led teacher training: New challenges for university teacher education. School Direct Research Project. Final Report. Manchester: Manchester Metropolitan University.

Burns, C., \& Myhill, D. (2004). Interactive or inactive? A consideration of the nature of interaction in whole class teaching, Cambridge Journal of Education, 34(1), 35-49.

Department for Education (2010). The importance of teaching. London: Department for Education.

Dowling, P. (1998). The sociology of mathematics education: Mathematical myths/pedagogic texts. London: Falmer Press.

Education, Audiovisual and Culture Executive Agency. (2011) Science Education in Europe: National Policies, Practices and Research. Brussels: Eurydice.

ENTEP: Dimitropoulos, A. (accessed 2016). The Bologna Process and teacher education structures in Europe: Creating a European Teacher Education Area. European Network on Teacher Education Policies.

Fennema, E., \& Nelson, B. (Eds.) (1997). Mathematics teachers in transition. New Jersey: Lawrence Erlbaum Associates Inc.

Foucault, M. (1989). The archaeology of knowledge. London: Routledge.

Freudenthal, H. (1991). Revisiting mathematics education: China lectures. Dordrecht: Kluwer.

Freeman, B., Marginson, S. \& Tytler, R. (eds.) (2015). The age of STEM: Policy and practice in science, technology, engineering and mathematics across the world. Oxon, UK; Routledge.

Fullan, M. (2001). The new meaning of educational change, New York: Teachers College Press.

Galton, M. (2002). A National Curriculum balance sheet. Education Review, 15(2), 1521.

Garcia, R., Saiz, M., \& Rivera, A. (2011). Cognitive cultural analysis of low achievement in TIMSS: Evaluating wrong answers in $8^{\text {th }}$ grade. In B. Ubuz (Ed.),

Gebremichael, A. (2011). Perceptions of relevance of prior experiences of mathematics in an Ethiopian preparatory school. In B. Ubuz (Ed.)

Goode, J. \& Margolis J. (2011). Exploring computer science: A case study of school reform. ACM Transactions on Computing Education. 11, 2, Article 12 .

Goos, M. (2005). A sociocultural analysis of the development of pre-service and beginning teachers' pedagogical identities as users of technology. Journal of Mathematics Teacher Education, 8(1), 35- 59.

Hammon, M (2011) Beliefs and ICT: what can we learn from experienced educators? Technology, Pedagogy and Education, 20 (3), 289-300.

Handal, B., \& Herrington, A. (2003). Mathematics teachers' beliefs and curriculum reform. Mathematics Education Research Journal, 15(1), 59-69. 
Hanley, C. \& Brown, T. (2016). Developing a university contribution to teacher education: creating an analytical space for learning narratives, Journal of Curriculum Studies.

Heywood, D. \& Parker, J. (2010). The Pedagogy of Physical Science. Dordrecht: Springer.

Hobson, A.J., Malderez, A. \& Tracey, L. (2009). Navigating initial teacher training: Becoming a teacher. London: Routledge.

Hodson, E., Smith, K. \& Brown, T. (2011). Reasserting theory in professionally-based initial teacher education, Teachers and Teaching, 18(2), 181-195.

Hudson, B and Zgaga, P, (eds.) (2008) Teacher education policy in Europe: a voice of higher education institutions. Monographs on Journal of research in teacher education, Faculty of Teacher Education, University of Umeå, Umeå.

Krogh, L. B. \& Thomsen, P. V. (2005). Studying students' attitudes towards science from a cultural perspective but with a quantitative methodology: border crossing into the physics classroom. International Journal of Science Education, 27, 281302.

Krzywacki, H., Koistinen, L., \& Lavonen, J. (2011). Assessment in Finnish mathematics education: Various ways, various needs. In B. Ubuz (Ed.),

Kynigos, C. \& Argyris, M. (2004). Teacher beliefs and practices formed during an innovation with computer-based exploratory mathematics in the classroom. Teachers and Teaching: theory and practice, 10(3), 247-273.

Lerman, S. (2000). A case of interpretations of 'social': A response to Steffe \& Thompson. Journal for Research in Mathematics Education, 31(2), 210-227.

Lloyd, G. M. (1999). Two teachers' conceptions of a reform-oriented curriculum: Implications for mathematics teacher development. Journal of Mathematics Teacher Education, 2(3), 227-252.

Ng, S., Lopez-Real, F., \& Rao, N. (2003). Early mathematics teaching: the relationship between teachers' beliefs and classroom practices, Proceedings of the 2003 joint meeting of PME and PMENA, vol. 3. Honolulu, USA: University of Hawaii.

Osbourne, J. \& Dillon, J. (2008). Science education in Europe: Critical reflections. London: Nuffield.

Pampaka, M., Williams, J., Hutcheson, G., Wake, G., Black, L., Davis, P., \& HernandezMartinez, P. (2012). The association between mathematics pedagogy and learners' dispositions for university study, British Educational Research Journal, 38(3), 473-496.

Remillard, J. (2000). Can curriculum materials support teachers' learning? Elementary School Journal, 11(4) 331-350.

Remillard, J. T. (2005). Examining key concepts in research on teachers' use of mathematics curricula. Review of Educational Research, 75(2), 211-246.

Remillard, J., \& Bryans, M. (2004). Teachers' orientations towards mathematics curriculum materials: implications for teacher learning. Journal for Research in Mathematics Education, 35(5), 352-388.

Remillard, J. T., \& Geist, P. K. (2002). Supporting teachers' professional learning by navigating openings in the curriculum. Journal of Mathematics Teacher Education, 5(1), 7-34.

Rivera Maulucci, M. (2010). Becoming an urban science teacher: Teacher learning as a collective performance of conceptions. In W-M. Roth (ed.) Re/structuring 
science education. Dordrecht: Springer.

Romberg, T. (1997). Mathematics in context: impact on teachers. In E. Fennema, \& B. Scott Nelson (Eds.) Mathematics teachers in transition. New Jersey: Lawrence Erlbaum Associates Inc.

Rowland, T. \& Ruthven, K. (Eds.) (2011). Mathematical knowledge in teaching. Dordrecht: Springer.

Rowland, T., Turner, F., Thwaites, A. \& Huckstep, P. (2009). Developing primary mathematics teaching: reflecting on practice with the Knowledge Quartet. London: Sage.

Sahin, C., Bullock, K., \& Stables, A. (2002). Teachers' beliefs and practices in relation to their beliefs about questioning at Key Stage 2. Educational Studies, 28(4), 371384.

Senger, E. (1999). Reflective reform in mathematics: The recursive nature of teacher change. Educational Studies in Mathematics, 37(3), 199-221.

Simon, M., \& Tzur, R. (1999). Explicating the teacher's perspective from the researchers' perspectives: generating accounts of mathematics teachers' practice. Journal for Research in Mathematics Education, 30(3), 252-264.

Skott, J. (2001). The emerging practices of a novice teacher: The roles of his school mathematics images. Journal of Mathematics Teacher Education, 4, 3-28.

Smith, K., Hodson, E. \& Brown, T. (2013a). Teacher educator changing perceptions of theory. Educational Action Research Journal. 25: 379-397.

Smith, K., Hodson, E. \& Brown, T. (2013b). The discursive production of classroom mathematics. Mathematics Education Research Journal. 25: 379-397.

Sorenson, P. (2014). Collaboration, dialogue and expansive learning: the use of paired and multiple placements in the school practicum. Teaching and Teacher Education. 44, 128-137.

Sorensen, P., Newton, L., \& McCarthy, S. (2012). Developing a science teacher education course that supports student teachers' thinking and teaching about the nature of science. Research in Science \& Technological Education, 30(1), 29-47.

Steffe, L., \& Kieran, T. (1994). Radical constructivism and mathematics education, Journal for Research in Mathematics Education, 25(6), 711-733.

Schwab, J. (1983). "The Practical 4: Something for curriculum professors to do." Curriculum Inquiry 13 (3): 239-265.

Sztajn, P. (2003). Adapting reform ideas in different mathematics classrooms: beliefs beyond mathematics. Journal of Mathematics Teacher Education, 6 (1), 53-75.

Tondeur, J., Siddiq, F., Scherer, R., \& van Braak, J. (2016). Time for a new approach to prepare future teachers for educational technology use: its meaning and measurement. Computers \& Education. 94, 134-150.

Torrance, H., \& Pryor, J. (2001). Developing formative assessment in the classroom: using action research to explore and modify theory. British Educational Research Journal, 27(5), 615-631.

Tytler, R., Swanson, D. \& Appelbaum, P. (2015). Subject matters of Science, Technology, Engineering, and Mathematics. In M. He, B. Schultz \& W. Schubert (eds.) The SAGE guide to curriculum in education. London: Sage.

Tzur, R., Simon, M., Heinz, K., \& Kinzel, M. (2001). An account of a teacher's perspective on learning and teaching mathematics: implications for teacher development. Journal of Mathematics Teacher Education. 4(3), 227-254. 
Ubuz, B. (Ed.) (2011) Proceedings of the $35^{\text {th }}$ Annual Conference of the International Group on the Psychology of Mathematics Education (Vol. 1, p. 340). Ankara, Turkey: Orta Dogu Teknik Üniversitesi [Middle East Technical University].

Van Zoest, L. R., \& Bohl, J. V. (2002). The role of reform curricular materials in an internship: The case of Alice and Gregory. Journal of Mathematics Teacher Education, 5, 265-288.

Voogt, J., \& Tondeur, J. (2015). Towards design-based approaches for ICT integration in African education. (J. Voogt \& J. Tondeur, Eds.) Technology Pedagogy and Education, 24(5), 527-537.

Wells, D. (2012). Computing in Schools: time to move beyond ICT? Research in Secondary Teacher Education, Vol 2, No. 1, pp8-13.

Wenger, E. (2000). Communities of practice: Learning, meaning and identity. Cambridge University Press. 